\title{
Aortic and mitral valve repair for anterior mitral leaflet perforation caused by severe aortic regurgitation
}

\author{
Kristof De Brabandere ${ }^{1}$, Jens-Uwe Voigt ${ }^{2}$, Stephen Rex ${ }^{3}$, Bart Meuris ${ }^{1}$, Peter Verbrugghe ${ }^{1}$ \\ ${ }^{1}$ Department of Cardiac Surgery, ${ }^{2}$ Deparment of Cardiology, ${ }^{3}$ Department of Anesthesiology, UZ Leuven, Leuven, Belgium \\ Correspondence to: Kristof De Brabandere. Department of Cardiac Surgery, UZ Leuven, Leuven, Belgium. Email: kristof.debrabandere@uzleuven.be.
}

\begin{abstract}
A 23-year-old man presented with acute onset of dyspnea on exert. Preoperative echocardiography showed a severe regurgitation of the bicuspid aortic valve (due to prolapse of the fused cusp) creating a jet directed through the defect in the anterior leaflet of the mitral valve. Both valves were repaired. Endocarditis was excluded with cultures and polymerase chain reaction (PCR). Postoperative course was uneventful.
\end{abstract}

Keywords: Aortic; mitral; valve; repair

Received: 13 March 2018; Accepted: 11 April 2018; Published: 11 May 2018.

doi: $10.21037 /$ jovs.2018.04.16

View this article at: http://dx.doi.org/10.21037/jovs.2018.04.16

\section{Introduction}

In mitral repair was the "French correction" promoted by Carpentier that probably started the road to current mitral repair strategies in many centers. Followed by the "respect rather than resect" approach that was suggested for the first time by Perier et al. $(1,2)$. When feasible, mitral valve repair has been the established treatment of choice over replacement in non-ischemic mitral valve insufficiency. It has the shortterm advantage of lower operative mortality, improved survival, better left-ventricular function preservation, shorter postoperative hospital stay, lower total costs and lower valve related complications including thromboembolism and bleeding events. Recent articles have also shown that, when comparing mitral repair with mitral valve replacement, repair is independently associated with superior long-term survival and similar rates of reoperation $(3,4)$.

Aortic valve sparing operations and aortic valve repair have evolved since the first attempts by Taylor et al. (5), especially the first reports in the nineties by Yacoub and David boosted the interest of many surgeons $(6,7)$. It is an emerging alternative to aortic valve replacement in the treatment of selected patients (8). Recent systematic reviews have shown that it has a low operative risk in specialized centers with an acceptable risk of reintervention that is better than the expected risk with a bioprosthetic valve replacement. Patients undergoing aortic valve repair seem also to have a substantially lower number of thromboembolic and bleeding events when compared to a mechanical valve replacement (9), and it improves their quality of life (10).

In this report we describe a case of both mitral and aortic valve repair.

\section{Case presentation}

A 23-year-old man presented with an acute onset of progressive dyspnea and palpitations. His history showed smoking, drug abuse, hyperventilation and shoulder dislocation. There was no family history. Clinical examination showed an apical systolic murmur.

Preoperative cardiac workup showed a normal blood sample, a normal sinusal electrocardiogram, a normal chest $\mathrm{X}$-ray and a normal coronary CAT-scan. Transthoracic and transesophageal echocardiography revealed a severe regurgitation of a bicuspid aortic valve due to prolapse of the fused cusp. The eccentric regurgitant jet of the aortic insufficiency was orientated directly in a central defect in the anterior mitral leaflet. There was a slightly lowered left ventricular function. It was theorized that the mitral perforation was caused by the regurgitant jet of the aortic valve. The defect in the anterior mitral leaflet was closed with a pericardial patch and an annuloplasty ring was 


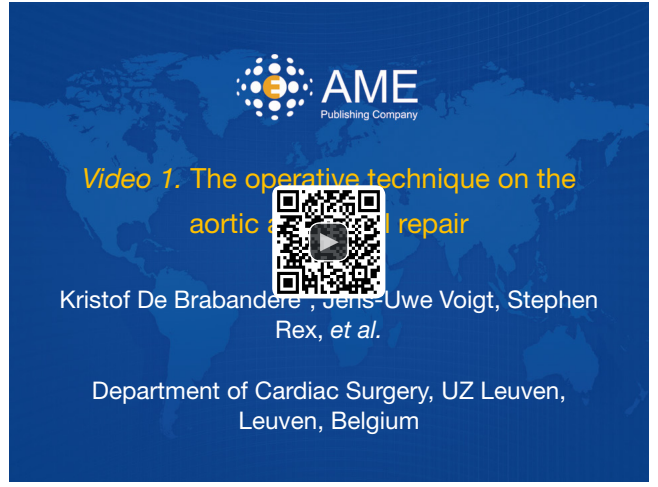

Figure 1 The operative technique on the aortic and mitral repair (11).

Available online: http://www.asvide.com/article/view/24728

used to stabilize the mitral annulus. The aortic valve was repaired with central plication stitches on the fused cusp and an external Dacron ring on the annulus and sinotubular junction.

Endocarditis was preoperatively doubtful since the major and minor Duke criteria for infective endocarditis where negative. Preoperatively endocarditis was excluded with cultures and polymerase chain reaction (PCR) being negative.

Postoperative echocardiography showed a complete closure of the defect in the anterior mitral leaflet and no residual regurgitation of both the mitral and the aortic valves. Postoperative course was uneventful.

\section{Patient selection and workup}

Patient selection for valve repair is mainly based on preoperative echocardiography. Considering the aortic valve, valve repair is offered to the patient when there are no calcifications or severely destructed leaflets in biand tricuspid valves. Nevertheless, a replacement or Ross procedure is always discussed with the patient. In the elderly or patients with a severe reduction in left ventricular function there is a low threshold to replace the valve. In the mitral valve, a repair is always the first choice, unless in severely destructed valves due to endocarditis, calcified annulus or severe rheumatic disease.

\section{Preoperative preparation}

The standard preoperative preparation consists of a standard blood sample, a chest X-ray, echo Doppler testing of the carotid arteries, an electrocardiogram, a transthoracic and a transesophageal echocardiography. Coronary catheterization is performed routinely unless in young patients without coronary risk factor or in aortic endocarditis. In the absence of severe left main disease, lung function testing is routinely performed.

\section{Equipment preference card}

Besides the standard cardiac surgery instruments, we use following instruments and tools:

* Liva Nova Memo-3D ReChord annuloplasty rings (Liva Nova, Saluggia, Italy);

* CardioCell pericardial patch (Admedus, Malaga, Western Australia);

* Gelweave Valsalva grafts (size 26-24) (Vascutec, Inchinnan, England);

* Effective height measuring caliper (Fehling Instruments, Karlstein, Germany);

* Hegar dilatators (size 20-34);

* A video tower and $0^{\circ}$ scope to film the complete procedure;

* Long-shafted instruments for the mitral repair;

* Kapp-Cosgrove retractor (Abott, Minnesota, USA).

\section{Procedure (Figure 1)}

The operation started with a standard median sternotomy, opening of the pericardium, dividing the thymus and placing stay sutures. Next heparin was administered, standard bicaval cannulation was performed and a left ventricular venting catheter was introduced through the right superior pulmonary vein. After cross clamping of the aorta, cardioplegia was administrated in a retrograde fashion because of the presence of the severe aortic regurgitation.

First, the left atrium was opened through Waterston's groove. After exposing the mitral valve, using the KappCosgrove retractor. The valve was analyzed. This showed a large perforation of the anterior leaflet (Figure 2).

This was closed by suturing a tailored CardioCell patch with prolene 5-0. Then annuloplasty sutures were placed. This was followed by sizing of the Memo 3D annuloplasty ring size 34 . This was then knotted into position. The mitral repair was evaluated with a "water test", showing a good posterior coaptation and no residual regurgitation (Figure 3).

After closure of the left atrium a full transverse aortotomy was performed. Aortic valve inspection showed a bicuspid 


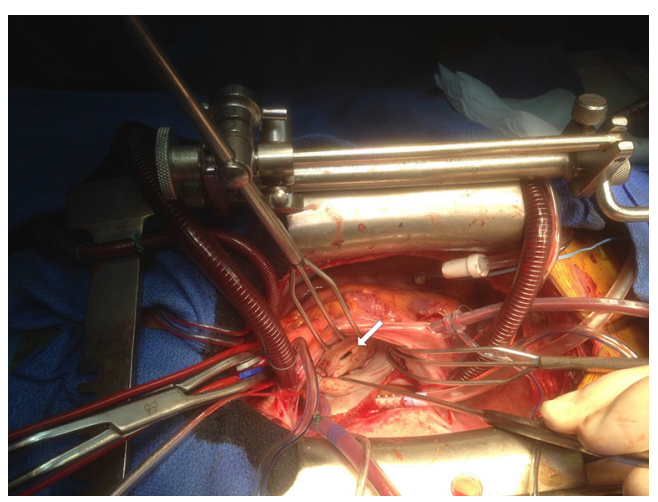

Figure 2 Intraoperative view of the mitral valve showing the perforation of the anterior leaflet. The arrow shows the perforation.

aortic valve with fusion of the left and right coronary cusps. Then the geometric height is measured using the caliper in the way it was described by Schäfers (12). This showed an effective height of the non-fused (non-coronary) cusp of 22 $\mathrm{mm}$. The next step was a deep complete dissection of the aortic root till the level of the aortic valve, followed by the creation of a tunnel under the coronary arteries.

As described in the "CAVIAAR technique", pledgetted subvalvular stitches were placed below each nadir and at the base of the interleaflet triangles $(8,10)$.

Then the free edges of both leaflets were aligned. Therefore, central plicating stitches using prolene 5-0 were placed on the free edge of the fused cusp. After placement of traction sutures on both commissures the effective height of the non-fused cusp was evaluated ( $9 \mathrm{~mm}$ ) (13).

A subvalvular reinforcement ring using a Dacron $26 \mathrm{~mm}$ graft was placed and fixated using the subvalvular sutures. The size was based on the previous measurement of the aortic annulus $(25 \mathrm{~mm})$ with Hegar dilators.

Afterwards the aorta was closed using a single layer continuous suture line of prolene 5-0. Finally, a $26 \mathrm{~mm}$ Dacron aortic ring was fixated on the level of the sinotubular junction as an external stabilization to protect the aorta against dilatation in the future.

After putting temporary pacemaker wires the patient was weaned of extracorporeal bypass. Immediate echocardiographic control showed a perfect result with no residual mitral or aortic regurgitation. Protamine was administered and the chest was closed in a conventional way.

\section{Role of team members}

The operative indication was set by the heart team.

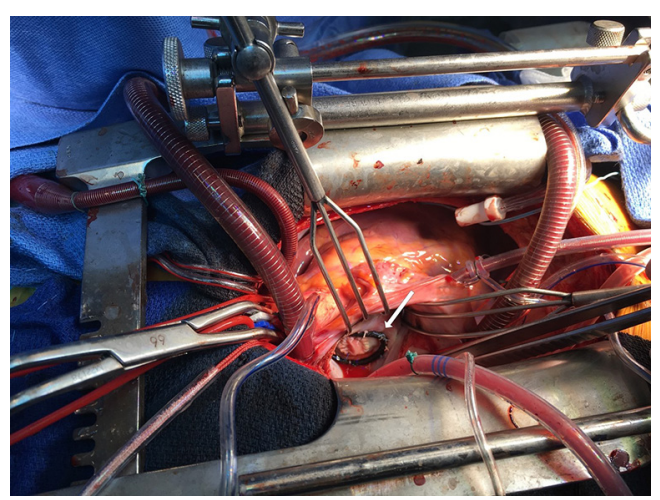

Figure 3 Intraoperative view of the mitral valve after repair of the anterior leaflet. The arrow shows the repaired perforation.

Preoperative workup was performed by the cardiologists. The senior anesthesiologist together with one or two trainees took care of arterial and central venous lines. They performed the endotracheal and a structured preoperative and postoperative transesophageal echocardiography to evaluate the valve lesions and the cardiac function.

The surgeon performed the main part of procedure with the aid of a first and sometimes a second assistant. The resident performed small parts of the operation under direct supervision of the primary surgeon.

A theater nurse assisted the surgeon during the entire procedure.

Postoperatively the patient recovered at the postanesthesia care unit where an anesthesiologist and nurses follow the recovery of the patient.

The perfusionist is responsible for the cardiopulmonary bypass system, temperature control of the patient, ultrafiltration and the administration of cardioplegia.

\section{Postoperative management}

As mentioned above, as there were no exclusion criteria, the patient was postoperatively treated using a fast recovery protocol. Possible but not absolute exclusion criteria are: younger than 18 years of age, redo surgery, morbid obesity, poor ventricular ejection fraction, pulmonary hypertension, COPD, renal insufficiency. Patient was weaned from the ventilator 1 hour postoperatively. Chest tubes and bladder probe were removed the day after surgery before transfer to the conventional ward. Postoperatively there was an episode of paroxysmal atrial fibrillation treated with $\beta$-blocker.

The patient left the hospital on day 6 postoperatively. 


\section{Tips, tricks and pitfalls}

\section{Mitral leaflet reconstruction}

We use one double stay-suture at the right side of the pericardium. The first suture is placed at the caudal border, the second more cranial at the level of the superior vena cava. Those sutures are then pulled behind the sternal retractor. This induces a slight turn of the heart and helps exposing the mitral valve.

The anterior mitral leaflet was reconstructed using decellularized bovine pericardium patch (CardioCel, Admedus, Milton, Queensland, Australia). This tissue might be more resistant to calcification when used in mitral valve reconstruction (14).

When sizing a mitral annuloplasty ring we mostly rely on the size of the anterior leaflet. When in doubt of two sizes the intercomissural distance might also come into play.

\section{Aortic valve repair}

Data suggest that stabilization of the annulus and ST junction might prevent failure of the reconstructed aortic valve $(15,16)$. Evaluation of the effective height is important to prevent failure of the repaired aortic valve. The height of the free edge of the leaflet should be at least $9 \mathrm{~mm}$ above the annular plane, a dedicated tool to measure this intra-operatively is recommended $(17,18)$ When placing the subvalvular stitches care should be taken to avoid the conduction tissue which anatomically lies at the interleaflet triangle between non- and right coronary cusp. We prefer to place the stich here at the outside of the aortic root.

Placement of the subvalvular stiches at the base of the interleaflet triangles in bicuspid aortic valves in $180^{\circ}$ through the annuloplasty ring might bring the commissural orientation closer to $180^{\circ}(17)$.

\section{Conclusions}

This case illustrates the feasibility of a successful repair of both the aortic and mitral valve in a patient with an anterior mitral leaflet perforation caused by severe aortic regurgitation.

\section{Acknowledgements}

None.

\section{Footnote}

Conflicts of Interest: The authors have no conflicts of interest to declare.

Informed Consent: Oral and written informed consent was obtained through our electronic medical file system (as for any patient).

\section{References}

1. Carpentier A. Cardiac valve surgery--the "French correction". J Thorac Cardiovasc Surg 1983;86:323-37.

2. Perier P, Hohenberger W, Lakew F, et al. Toward a new paradigm for the reconstruction of posterior leaflet prolapse: midterm results of the "respect rather than resect" approach. Ann Thorac Surg 2008;86:718-25; discussion 718-25.

3. McNeely CA, Vassileva CM. Long-term outcomes of mitral valve repair versus replacement for degenerative disease: a systematic review. Curr Cardiol Rev 2015;11:157-62.

4. Kim GS, Kim JB, Han S, et al. Mitral valve repair versus replacement for moderate-to-severe mitral regurgitation in patients undergoing concomitant aortic valve replacement. Interact Cardiovasc Thorac Surg 2014;18:73-9.

5. Taylor WJ, Thrower WB, Black H, et al. The surgical correction of aortic insufficiency by circumclusion. J Thorac Surg 1958;35:192-205

6. Yacoub MH, Gehle P, Chandrasekaran V, et al. Late results of a valve-preserving operation in patients with aneurysms of the ascending aorta and root. J Thorac Cardiovasc Surg 1998;115:1080-90.

7. David TE, Feindel CM. An aortic valve-sparing operation for patients with aortic incompetence and aneurysm of the ascending aorta. J Thorac Cardiovasc Surg 1992;103:61721; discussion 622 .

8. Lansac E, Di Centa I, Vojacek J, et al. Valve sparing root replacement: the remodeling technique with external ring annuloplasty. Ann Cardiothorac Surg 2013;2:117-23.

9. Gillinov AM, Blackstone EH, Cosgrove DM 3rd, et al. Mitral valve repair with aortic valve replacement is superior to double valve replacement. J Thorac Cardiovasc Surg 2003;125:1372-87.

10. Aicher D, Holz A, Feldner S, et al. Quality of life after aortic valve surgery: replacement versus reconstruction. J Thorac Cardiovasc Surg 2011;142:e19-24. 
11. De Brabandere K, Voigt JU, Rex S, et al. The operative technique on the aortic and mitral repair. Asvide 2018;5:510. Available online: http://www.asvide.com/ article/view/24728

12. Schäfers HJ, Schmied W, Marom G, et al. Cusp height in aortic valves. J Thorac Cardiovasc Surg 2013;146:269-74.

13. Lansac E, Bouchot O, Arnaud Crozat E, et al. Standardized approach to valve repair using an expansible aortic ring versus mechanical Bentall: early outcomes of the CAVIAAR multicentric prospective cohort study. J Thorac Cardiovasc Surg 2015;149:S37-45.

14. Brizard CP, Brink J, Horton SB, et al. New engineering treatment of bovine pericardium confers outstanding resistance to calcification in mitral and pulmonary implantations in a juvenile sheep model. J Thorac

doi: 10.21037/jovs.2018.04.16

Cite this article as: De Brabandere K, Voigt JU, Rex S, Meuris B, Verbrugghe P. Aortic and mitral valve repair for anterior mitral leaflet perforation caused by severe aortic regurgitation. J Vis Surg 2018;4:99.
Cardiovasc Surg 2014;148:3194-201.

15. Zeeshan A, Idrees JJ, Johnston DR, et al. Durability of Aortic Valve Cusp Repair With and Without Annular Support. Ann Thorac Surg 2018;105:739-48.

16. Lansac E, Di Centa I, Sleilaty G, et al. Long-term results of external aortic ring annuloplasty for aortic valve repair. Eur J Cardiothorac Surg 2016;50:350-60.

17. Aicher D, Kunihara T, Abou Issa O, et al. Valve configuration determines long-term results after repair of the bicuspid aortic valve. Circulation 2011;123:178-85.

18. Kunihara T, Aicher D, Rodionycheva S, et al. Preoperative aortic root geometry and postoperative cusp configuration primarily determine long-term outcome after valvepreserving aortic root repair. J Thorac Cardiovasc Surg 2012;143:1389-95. 